\title{
Genetic correlation between biomass allocation to male and female functions in a natural population of Ipomopsis aggregata
}

\author{
DIANE R. CAMPBELL \\ Department of Ecology and Evolutionary Biology, University of California, Irvine, CA 92697, U.S.A., and Rocky \\ Mountain Biological Laboratory, Crested Butte, CO 81224, U.S.A.
}

\begin{abstract}
Models for sex allocation assume that increased expenditure of resources on male function decreases the resources available for female function. Under some circumstances, a negative genetic correlation between investment in stamens and investment in pistil and seeds is expected. This study used a nested half-sibship design to test for genetic correlations between biomass of stamens, corolla, calyx, pistil and seeds in the hermaphroditic herb Ipomopsis aggregata. Over 5000 seeds from 32 paternal half-sib families and 229 maternal full-sib families were planted under natural field conditions and followed for up to 9 years until blooming. Stamen mass and corolla mass exhibited moderately high levels of additive genetic variance, and heritabilities of 0.32 and 0.40 , respectively. Genetic correlations, as estimated with family mean correlations, were all either positive or not significantly different from zero. Even after controlling for plant size and flower number as indices of resource acquisition, paternal half-sib families that invested more biomass in stamens also invested more in the pistil and in the corolla.
\end{abstract}

Keywords: genetic correlation, genetic variation, Ipomopsis, plant reproduction, sex allocation.

\section{Introduction}

Flowering plants exhibit an extraordinary diversity of breeding systems (Yampolsky \& Yampolsky, 1922) that has inspired development of a rich body of theory. This theory builds on two hypotheses. One hypothesis focuses on the genetic consequences of selfing. It suggests that separate sexes are favoured when selection for outcrossing results from high inbreeding depression combined with frequent selfing (Charlesworth \& Charlesworth, 1978). The second hypothesis focuses on resource allocation to the two sexual functions. It suggests that separate sexes are favoured when increasing investment of resources in a single sexual function results in an accelerating fitness pay-off through that same sexual function (Charnov, 1982; Lloyd, 1984). Diminishing fitness returns on investment instead make hermaphroditism evolutionarily stable. This model also predicts the evolutionarily stable allocation of resources to male function within a population of hermaphrodites. The two hypotheses are not mutu-

Correspondence. E-mail: dcampbel@orion.oac.uci.edu ally exclusive, and selfing may impose extra restrictions on the stability of hermaphroditism (Charlesworth \& Charlesworth, 1981).

Central to models built on resource allocation is the assumption of a common resource base, such that increased expenditure on male function, for example on stamens, decreases resources available for female function, the pistil and seeds (Charnov, 1982). Genotypes that devote more resources to male function should retain less for female function, leading to the expectation of a negative genetic correlation between resources in male and female functions (Reznick, 1985; Stanton \& Galloway, 1990). If, however, genotypes also vary in ability to acquire resources from the environment, this tradeoff may not be observed (Laporte \& Delph, 1996). Provided that genetic variation in resource acquisition is sufficiently large compared with variation in resource allocation, the genetic correlation may even be positive (van Noordwijk \& de Jong, 1986).

In recent years data have accumulated on the phenotypic correlations between allocation to male and female functions in flowering plants (e.g. Stanton \& Preston, 1988; Goldman, 1991; Sakai \& 
Weller, 1991). Phenotypic correlations can, however, differ from genetic correlations, as they also include effects of environmental variation that may often alter male and female reproduction in the same direction. A smaller set of studies has manipulated investment to evaluate physiological costs of reproduction (Goldman, 1991). Development of theory has, however, outpaced data acquisition in this area. There are remarkably few estimates of genetic correlation between allocation to male and female functions in terms directly applicable to sex allocation models (Ågren \& Schemske, 1995), and the few studies that exist are restricted to greenhouse or other artificial settings.

Choosing the appropriate traits to describe sex allocation is not straightforward, as current models do not all agree on the parameters to measure. One difficulty is that the timing of flower and seed production differ, making it unclear whether they share a common resource pool. If they do, seed production should be included as another aspect of female investment along with gynoecium production as in Charlesworth \& Charlesworth (1981) and Charnov (1982). An alternative is to separate initial allocation at the time of flowering from seed production (Charlesworth \& Charlesworth, 1987). If it is feasible to determine the extent to which biomass or nutrients invested in the flowers are recovered and reallocated to seed production, then dynamic measures of allocation could be used to model sex allocation more accurately (Ashman, 1994a). A second difficulty is that allocation patterns can depend on whether the currency is biomass or nutrient content (Lovett Doust \& Harper, 1980; Ashman, 1994b). Estimation of genetic correlations requires a large number of plants, and so calls for a simple measure of allocation, such as biomass. Although biomass is a static measure providing no information on the extent of resource reallocation, the range of possibilities can be bracketed by determining both initial biomass allocation at the time of flowering and final allocation including seed production (Campbell, 1992).

The purpose of this study was to measure genetic correlations between allocation to male and female functions in Ipomopsis aggregata ssp. aggregata (Polemoniaceae). This hermaphroditic herb exhibits extensive phenotypic variation in both initial and final sex allocation, as measured by the partitioning of reproductive biomass into the androecium, gynoecium, attractive floral structures and seeds (Campbell, 1992). Moreover, this variation is known to have important fitness consequences (Campbell, 1989a, 1992; Campbell et al., 1994). Here the extent of genetic variation in these sex allocation traits is determined. The experimental design allowed additive genetic covariation between traits to be estimated under natural field conditions.

\section{Materials and methods}

Ipomopsis aggregata is widespread in the mountains of the western U.S. At the study site at the Rocky Mountain Biological Laboratory (RMBL), Gunnison County, CO, it has a monocarpic life history (Waser \& Price, 1989). Seeds produced in August-September germinate the next spring to produce a rosette of leaves. The rosette overwinters, before flowering at age 2-10 years (Campbell, 1997). A plant produces hermaphroditic flowers (mean $=84$ flowers in Campbell, 1989b) that open over 4-7 weeks. The red flowers are trumpet-shaped, with five anthers presented near the opening of the corolla tube and a stigma that can be inserted or exserted. Plants are self-incompatible. The flowers are protandrous and produce nectar in both staminate and pistillate phases. Most pollination results from visits by broadtailed (Selasphorus platycercus) and rufous hummingbirds (Selasphorus rufus; Campbell et al., 1991).

Many aspects of sex allocation vary among plants growing near the RMBL (Campbell, 1992). One way of describing this variation is to calculate phenotypic gender based on biomass allocations to the pistil and stamens. Phenotypic gender (calculated according to Lloyd, 1979) ranged from 0.34 to 0.77 female in three populations studied by Campbell (1992). Pistil and stamen biomasses also correlate with other floral features that influence fitness components. Pistil weight correlates positively with stigma exsertion and with the proportion of time that the flowers spend in the pistillate rather than the staminate phase (Campbell, 1989a, 1992), and this last trait has a strong influence on the amount of pollen received on stigmas (Campbell et al., 1994). Stamen weight correlates with pollen production and with the width of the corolla tube (Campbell, 1992), both of which influence export of pollen from flowers by hummingbirds (Campbell et al., 1996). As a result, plants vary not only in phenotypic gender but also in functional gender based on estimates of female and male fitness components (Campbell, 1989a).

\section{Design of the quantitative genetic study}

To estimate additive genetic variation in sex allocation, a paternal half-sibship design was used (details in Campbell, 1996). Crosses were performed in each year from 1986 to 1989. Except in 1986, when plants 
were caged and hand-pollinated in the field, the parents were potted and maintained in a greenhouse. In each year, 40 parent plants were obtained from each of two different populations at RMBL. Of the 40 plants, four were chosen to serve as pollen donors (males). Each male was mated to a different set of nine pollen recipients (females). The complete design called for 288 full-sib families nested within 32 male parents nested within eight populations nested within 4 years.

The seeds were planted into the natural meadow within $200 \mathrm{~m}$ of the source populations. In each year, seeds were planted in a randomized block design with one seed from each full-sib family per block and 25 blocks (20 in 1986). Seeds were planted in grids at a spacing of $7 \mathrm{~cm}(5 \mathrm{~cm}$ in 1987). Some seeds were consumed, while still in fruits, by the anthomyiid fly Hylemya sp., reducing the number planted to 5439 and the number of full-sib families to 229 .

\section{Measurements of sex allocation traits}

In June (1987-94) or July (1995) of each successive year the presence or absence of each individual and whether it was in a vegetative or flowering stage were recorded. By the end of the 1995 season, 390 plants had bloomed and then died. Most other plants had died before flowering, leaving only 61 survivors (all but two were planted in 1988 or 1989) that were not included in the analysis.

Reproductive allocation traits were measured for each of the 390 plants that bloomed. The traits included the biomass of stamens, pistil, corolla and calyx. Flowers were sampled once per week throughout the blooming season. For most plants at least five flowers were sampled. If fewer than two measurements were obtained, the plant was dropped from the analysis. The pistil, corolla and calyx were dissected from female-phase flowers (the pistil is not fully developed in male-phase flowers) and ovendried to constant weight before weighing to the nearest $0.01 \mathrm{mg}$. Because the anthers dehisce as the flower opens, the dry weight of the stamens was determined from elongated flower buds rather than from open flowers. Buds were also collected once per week.

At the end of the flowering season, all seeds were collected from each plant. Fruits were collected every 2 days, just before dehiscence and release of seeds. As calyces of aborted fruits and unpollinated flowers also remain on the plant, these collections allowed the total flowers produced over the season as well as the total seed production to be deter- mined. Estimates took into account the small fraction of flowers that had been sampled before seed formation. Samples of at least 50 mature seeds from each plant were weighed to determine average wet seed mass. Wet mass was converted to dry mass based on the conversion factor obtained by Campbell (1992).

From these measurements, sex allocation was determined both on a per flower and on a per plant basis. At the per flower level, the mean absolute biomasses of the stamens, pistil, corolla and calyx were calculated. Biomass of the seeds was obtained by multiplying the mean seeds per flower by the mean seed biomass. The proportion of unilateral costs allocated to male function at the time of flowering, stamens/(stamens + pistil), was then calculated, and the final proportion allocated to male function, stamens/(stamens + pistil + seed). Allocation was also estimated on a per plant basis by multiplying the per flower biomass for stamens, pistil, corolla, calyx and seeds by the number of flowers.

\section{Statistical analysis of genetic variation and covariation}

The paternal half-sibship design allowed estimation of additive genetic variance for each trait. A fully nested random model was used, with population nested within planting year, male parent nested within population and female parent nested within male parent. Type I variance components were computed using procedure NESTED in SAS (6.04). Because sample sizes were unequal, statistical significance was checked with the Satterthwaite approximation implemented by the RANDOM statement in procedure GLM. Additive genetic variance $\left(V_{\mathrm{A}}\right)$ was estimated as four times the male variance component, and heritability as four times the proportion of within-population variance explained by the male parent. The additive genetic coefficient of variation $\left(C V_{\mathrm{A}}\right)=100 \sqrt{ } V_{\mathrm{A}} / \bar{x}$, where $\bar{x}$ is the mean phenotypic value of the trait (Houle, 1992), was also calculated.

Genetic correlations between traits were estimated with family mean correlations. First, paternal family means were found by averaging across offspring of a single mother and then averaging over females. Because of the hierarchical nested design, correlations between paternal family means could result from common effects of planting year or source population as well as from genetic correlations. To remove these higher sources of correlation, family means were first subjected to a preliminary ANOVA with the factors of planting year and popula- 
tion nested within planting year, and the residual values obtained. Pearson correlations between the residual values for pairs of traits were then calculated.

Variation in acquisition of resources would tend to generate positive correlations between investment in male and female function that might obscure an underlying trade-off. Although resource acquisition was not measured directly, two traits likely to relate to resource acquisition were measured: number of flowers produced and size of the vegetative rosette (data in Campbell, 1997). Both of these traits respond to nutrient additions (Campbell \& Halama, 1993), and size of the rosette also exhibits additive genetic variation (Campbell, 1997). It was decided to analyse size at age 4 years because that was the greatest age reached by at least one offspring in every paternal family. Size was estimated by multiplying the length of the longest leaf (in $\mathrm{mm}$ ) by the number of leaves. For those pairs of sex allocation traits with detectable family mean correlations, a multiple regression of one trait mean on the other trait mean and vegetative size was then performed. A second multiple regression used flower number rather than vegetative size as the index of resource acquisition. These regressions tested for a negative relationship between biomass invested in male and female functions, when plant size was held constant.

\section{Results}

\section{Genetic variation}

The corolla was the single most expensive reproductive function, accounting for 42 per cent on average of biomass invested in reproduction (Table 1 ). Ten per cent and 6 per cent were invested in stamens and pistil, respectively, with the remainder in calyx and seeds. All of these biomass traits show phenotypic variation among plants in natural populations (Campbell, 1992). For corolla mass and stamen biomass, this phenotypic variation also had a significant additive genetic component $(P<0.05$, Table 1). Narrow-sense heritabilities were estimated as 0.32 and 0.40 for corolla mass and stamen biomass, respectively. In contrast, no significant additive genetic variation was detected in calyx mass, pistil mass or seeds mass at the per-flower level. The genetic coefficient of variation for mass of seeds produced by a flower was at least as high as for corolla and stamen mass, suggesting that the lack of statistical significance and low estimate of heritability $(0.07)$ resulted in this case from relatively high environmental variation.

In spite of considerable additive genetic variation in biomass of the stamens $\left(C V_{\mathrm{A}}=12.6, P<0.01\right)$, no significant genetic variation in costs allocated to male function on a proportional basis could be detected. The final proportion allocated to male function, stamens/(stamens + pistil + seeds), averaged 0.27 , with an estimated narrow-sense heritability of $0.08(P>0.05)$ and additive genetic coefficient of variation equal to 11.9 . The proportion allocated to male function at flowering, stamens/(stamens + pistil), averaged 0.63 .

Biomasses of all four floral parts varied signficantly among female parents in a fully nested ANOVA (Table 2). For calyx biomass and pistil biomass, which showed no evidence of additive genetic variation, this variation could result from dominance variation or maternal effects. Assuming no dominance variance, it is possible to set an upper bound on variance attributable to a common maternal environment by subtracting the male variance component from the female component (Falconer, 1989). Following this procedure, maternal effects could account for up to 7 per cent of variation in corolla

Table 1 Mean values, additive genetic coefficients of variation $\left(C V_{\mathrm{A}}\right)$, and within-population narrow-sense heritabilities $\left(h^{2}\right)$ of per-flower biomass traits for Ipomopsis aggregata

\begin{tabular}{lcccc}
\hline Trait & $\begin{array}{c}\text { No. of } \\
\text { plants }\end{array}$ & Mean (mg) & $\begin{array}{c}\text { Additive genetic } \\
\text { coefficient of variation }\end{array}$ & Heritability \\
\hline Corolla mass & 388 & 4.19 & $9.3^{*}$ & $0.32^{*}$ \\
Calyx mass & 388 & 1.46 & 8.0 & 0.14 \\
Stamens mass & 389 & 0.94 & $12.6^{* *}$ & $0.40^{* *}$ \\
Pistil mass & 388 & 0.55 & 0.0 & 0.0 \\
Seeds mass & 320 & 2.75 & 15.4 & 0.07 \\
\hline
\end{tabular}

${ }^{*} P<0.05$ in a fully nested random aNOVA, ${ }^{* *} P<0.01$. 
Table 2 Per cent variance components (Type I) in a fully nested ANOva of average per-flower biomass for Ipomopsis aggregata

\begin{tabular}{lrccccr}
\hline & & \multicolumn{5}{c}{ Per cent variance } \\
\cline { 3 - 7 } $\begin{array}{l}\text { Source of } \\
\text { variation }\end{array}$ & d.f. & $\begin{array}{c}\text { Corolla } \\
\text { mass }\end{array}$ & $\begin{array}{c}\text { Calyx } \\
\text { mass }\end{array}$ & $\begin{array}{c}\text { Stamens } \\
\text { mass }\end{array}$ & $\begin{array}{c}\text { Pistil } \\
\text { mass }\end{array}$ & $\begin{array}{r}\text { Seeds } \\
\text { mass }\end{array}$ \\
\hline $\begin{array}{l}\text { Planting year } \\
\text { Population }\end{array}$ & 3 & 0.0 & 8.5 & 0.6 & 0.9 & 12.5 \\
Male & 4 & 2.2 & 0.0 & 0.0 & 0.4 & 2.5 \\
Female & 24 & $7.7^{*}$ & 3.2 & $10.0^{*} \dagger$ & 0.0 & 1.5 \\
Offspring & 132 & $14.9^{*}$ & $14.6^{*}$ & $17.7^{* *}$ & $18.7^{* *}$ & 1.2 \\
\hline
\end{tabular}

${ }^{*} P<0.05,{ }^{*} P<0.01$. $\uparrow P=0.013$ and $P=0.003$ with and without the

Satterthwaite correction, respectively.

biomass, 11 per cent of variation in calyx biomass, 8 per cent of variation in stamens biomass, and 19 per cent of variation in pistil biomass.

\section{Genetic correlations}

Contrary to the expectation of a trade-off in sex allocation, paternal families that invested more in male function, as indicated by heavier stamens, did not invest less in female function. All estimates of genetic correlations between biomass of the stamens and other reproductive parts were zero or positive (Table 3). In particular, biomass of the stamens showed a positive family mean correlation with biomass of the pistil, an indicator of unilateral female investment at the time of flowering $(r=0.40$, $P=0.02)$. Whether that association represents a genetic correlation remains equivocal, because a genetic correlation requires additive genetic variation in both traits and none could be detected in mass of the pistil. In contrast, corolla mass did show considerable genetic variation, making the estimate of correlation between biomass in stamens and corolla of particular interest. That genetic correlation between investment in a male structure and an attractive structure was strongly positive (Fig. 1, $r=0.54, P=0.001$ ).

Although the biomasses of floral parts were strongly intercorrelated, biomass of the seeds produced per flower was genetically uncorrelated with all floral parts except for the biomass of the pistil $(r=0.55, P<0.01)$. And unlike investment in female function at the time of flowering, final investment as indicated by the combined mass of pistil and seeds per flower, showed no detectable genetic correlation with biomass of the stamens $(r=-0.09$, $P=0.61)$.
Genetic correlations may differ depending on whether they are calculated on the basis of the average per-flower investment or whole-plant investment, for at least two reasons. Any genetic variation in flower number will contribute to a positive correlation between biomasses of two floral parts at the whole-plant level. In addition, genetic correlations of sex allocation traits with flower number can induce discrepancies. Calyx mass and pistil mass were both positively genetically correlated with number of flowers produced by the plant (Table 3 ). Recalculating family mean correlations based on whole-plant totals led to much larger values than those obtained using average per-flower biomasses. All correlations between reproductive parts at the time of flowering were strongly positive, with estimates ranging from $r=0.87$ to 0.97 (all $P<0.0001$ ). In addition, total seed biomass for the whole plant showed high family mean correlations with biomasses of all floral parts ( $r=0.71-0.89$, all $P<0.0001)$.

Phenotypic correlations were in general similar to the genetic correlations (Table 3). A regression predicting the genetic correlation from the phenotypic correlation did not deviate significantly from the line of equality (intercept $=0.13 \pm 0.07$ (SE) and slope $=0.82 \pm 0.24, N=15$ pairs of traits). The most obvious exception to this pattern of similarity involved the association between biomass of the pistil and biomass of the seeds, which exhibited a high paternal mean correlation $(r=0.55)$ but a low or zero phenotypic correlation $(r=0.06)$, suggesting that the environmental correlation is negative.

\section{Effects of plant size}

The positive family mean correlations between allocation to stamens and allocation to other repro- 
ductive parts did not result from variation in plant size, at least not as measured by size of the vegetative rosette or flower number. When plant size was included in a multiple regression, the partial regression coefficient of mean pistil mass on mean stamens mass was still positive $(P<0.05$, Table 4$)$. Similarly, the partial regression of mean corolla mass on mean stamens mass was also positive $(P<0.01)$. Thus, even controlling for plant size as an indicator of resource acquisition, families that inves-
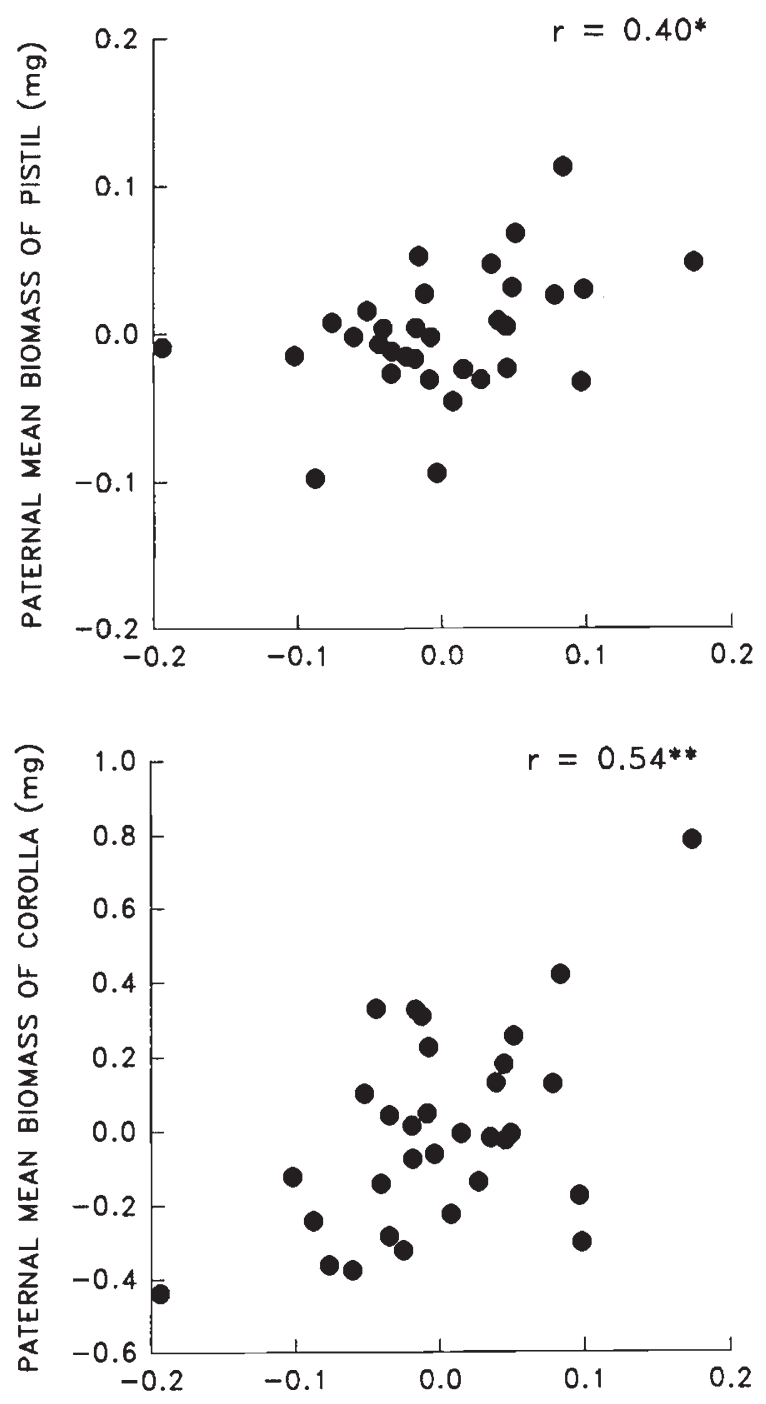

PATERNAL MEAN BIOMASS OF STAMENS $(\mathrm{mg})$

Fig. 1 Scatter plots illustrating the positive paternal mean correlations between biomass of the stamens and biomass of the pistil and corolla in a flower of Ipomopsis aggregata. Values plotted are the residuals from a preliminary model that removed the variation attributable to planting year and source population. ${ }^{*} P<0.05,{ }^{*} P<0.01$. ted more in stamens also invested more biomass in the pistil and in the corolla.

\section{Discussion}

Sex allocation theory assumes that genotypes investing more resources in male reproduction have less available for female reproduction. All else being equal, if this assumption is met, the simple expectation is a negative genetic correlation between investment in the two sexual functions. Here no evidence was found for such negative genetic correlations. Instead, all paternal family mean correlations between biomass investment in stamens and biomass in other reproductive parts were either positive (such as for the corolla and pistil), or not demonstrably different from zero.

Positive genetic correlations between allocations to alternative functions have been described for a variety of life history traits and for resistance to herbivory (reviews by Houle, 1991; Simms, 1992). Sex allocation in hermaphroditic or monoecious plants has received little prior attention, but Ågren \& Schemske (1995) detected a positive broad-sense genetic correlation between investment in male and female flowers of Begonia semiovata. Several explanations for such positive correlations have been proposed. First, genotypes may vary in their ability to acquire resources. This can take the form of variation in the total resources available for male and female reproduction (van Noordwijk \& de Jong, 1986), leading to positive genetic covariance between allocation traits at a mutation-selection equilibrium (Houle, 1991). Alternatively, genotypes that differ in sex expression may as a consequence differ in acquisition, because of differences in photosynthetic rate or in carbon-fixing structures (Delph \& Meagher, 1995). Here it was attempted to control for variation in resource acquisition by including plant size as a covariate and it was found that paternal families of similar size that allocated more to stamens still allocated more to the corolla and pistil. Rosette size and flower number might, however, be poor indicators of carbon acquisition, so that variation in resource acquisition remains a possible explanation.

A second possibility is that allocation involves partitioning resources among traits other than those measured (Charlesworth, 1990). In this study some paternal families had larger corollas and stamens, but there might be a trade-off between total reproduction and vegetative growth. Indeed data reported elsewhere suggest a negative genetic correlation between width of the corolla tube (which correlates 
Table 3 Paternal mean correlations (above diagonal) and phenotypic correlations (below diagonal) for Ipomopsis aggregata. Biomass traits are average values per flower. Values given are Pearson product-moment correlation coefficients. The paternal mean correlations were estimated on residual values after removing the effects of planting year and population

\begin{tabular}{lllllll}
\hline & $\begin{array}{c}\text { Corolla } \\
\text { mass }\end{array}$ & $\begin{array}{c}\text { Calyx } \\
\text { mass }\end{array}$ & $\begin{array}{c}\text { Stamens } \\
\text { mass }\end{array}$ & $\begin{array}{c}\text { Pistil } \\
\text { mass }\end{array}$ & $\begin{array}{c}\text { Seeds } \\
\text { mass }\end{array}$ & $\begin{array}{l}\text { No. of } \\
\text { flowers }\end{array}$ \\
\hline Corolla mass & & $\mathbf{0 . 6 4 * * * *}$ & $\mathbf{0 . 5 4 * *}$ & $\mathbf{0 . 5 2} * *$ & -0.11 & 0.08 \\
Calyx mass & $\mathbf{0 . 5 1 * * * *}$ & & 0.28 & $\mathbf{0 . 6 2} * * *$ & 0.19 & $\mathbf{0 . 4 2}$ \\
Stamens mass & $\mathbf{0 . 3 9} * * * *$ & $\mathbf{0 . 1 4} * *$ & & $\mathbf{0 . 4 0}$ & -0.11 & 0.14 \\
Pistil mass & $\mathbf{0 . 6 2 * * * *}$ & $\mathbf{0 . 4 7 * * * *}$ & $\mathbf{0 . 2 6} * * * *$ & & $\mathbf{0 . 5 5 * *}$ & $\mathbf{0 . 4 6 * *}$ \\
Seeds mass & 0.00 & -0.10 & $\mathbf{0 . 1 4} *$ & 0.06 & & 0.15 \\
No. flowers & $\mathbf{0 . 2 1} * * * *$ & $\mathbf{0 . 2 5} * * * *$ & $\mathbf{0 . 1 4} * *$ & $\mathbf{0 . 3 2} * * * *$ & -0.04 & \\
\hline
\end{tabular}

${ }^{*} P<0.05,{ }^{*} P<0.01,{ }^{* * *} P<0.001,{ }^{* * * *} P<0.0001 . N=32$ for family mean correlations. $N=315-389$ for phenotypic correlations.

positively with stamen mass and corolla mass) and survival from seedling to flowering (Campbell, 1997). Genetic correlations between traits measured here and survival from seedling to flowering were thus tested for (see Campbell, 1997), but no detectable paternal mean correlation with biomass of any floral part $(r=-0.15-0.20, N=32$ families $)$, the mass of the flower and seeds $(r=-0.23)$, or total mass of all flowers $(r=0.14)$ was found. A trade-off between reproductive investment and vegetative survival appears unlikely.

A third possibility is strong selection to maintain a positive genetic correlation. The highest genetic correlation estimated here was between mass of the stamens and mass of the corolla. Although few comparable estimates of genetic correlations are available, corolla (or petal) size and pollen production have been found to correlate phenotypically in several other species (reviewed in Stanton \& Galloway, 1990). Stanton \& Galloway (1990) suggested that positive genetic correlation may be retained between these traits either because of their close developmental ties, or because of strong selection through male function for greater allocation to attractive structures to increase pollen export from flowers (Stanton \& Preston, 1988). In I. aggregata

Table 4 Multiple regressions on biomass of the stamens and a measure of plant size for Ipomopsis aggregata. Size of the rosette was measured by the length of the longest leaf times the number of leaves at age 4 years. Analysis was performed on the residual values for paternal family means from preliminary ANOVAS that removed the effects of planting year and population

\begin{tabular}{llrrrr}
\hline $\begin{array}{l}\text { Dependent } \\
\text { variable }\end{array}$ & $\begin{array}{l}\text { Source of } \\
\text { variation }\end{array}$ & d.f. & $\begin{array}{c}\text { Partial } \\
\text { regression } \\
\text { estimate }\end{array}$ & \multicolumn{1}{c}{$F$} & $P$ \\
\hline Pistil biomass (mg) & Stamens biomass (mg) & 1 & 0.21564 & 5.02 & 0.0329 \\
& No. of flowers & 1 & 0.00094 & 4.67 & 0.0392 \\
& Error & 29 & & & \\
Pistil biomass (mg) & Stamens biomass (mg) & 1 & 0.24947 & 5.92 & 0.0213 \\
& Size of rosette (mm) & 1 & -0.00001 & 0.65 & 0.4279 \\
& Error & 29 & & & \\
Corolla biomass (mg) & Stamens biomass (mg) & 1 & 2.15848 & 13.14 & 0.0011 \\
& No. of flowers & 1 & -0.00269 & 1.01 & 0.3231 \\
& Error & 29 & & & \\
Corolla biomass (mg) & Stamens biomass (mg) & 1 & 2.07116 & 11.73 & 0.0019 \\
& Size of rosette (mm) & 1 & 0.00002 & 0.06 & 0.8083 \\
& Error & 29 & & & \\
\hline
\end{tabular}


larger corollas do not necessarily attract more pollinator visits (see divergent results of Campbell et al., 1991; Mitchell, 1994), but they do appear to increase the effectiveness of pollen export by allowing greater penetration of a hummingbird's bill into the flower (Campbell et al., 1996). Thus, it seems plausible that selection could favour an association between high male function and large corolla size in this system.

A final category of explanations concerns the currency in which allocation was measured. Reproductive allocation can differ depending on whether it is measured in terms of biomass or various nutrients, such as nitrogen, phosphorus or potassium (Ashman, 1994b). In addition, a static measure such as biomass is not necessarily a good predictor of the physiological cost of synthesis and maintenance (Chapin, 1989; Ashman, 1994a). In I. aggregata, nutrient additions to the soil can enhance flower number and seed production (Campbell \& Halama, 1993), suggesting that nutrient contents might provide more sensitive measures of cost (Chapin, 1989). It would be interesting to compare genetic correlations based on biomass vs. nutrients, employing either sib analysis or artificial selection for increased allocation to male function.

\section{Acknowledgements}

I am grateful to T. Forbis, K. Halama, C. Jamison, C. D. Janus, D. Massart, L. McGrath, E. MeléndezAckerman and A. Yarger for assistance and to A. Sakai and S. Weller for comments on the manuscript. Financial support was provided by NSF grants BSR-8516498, BSR-8996306 and DEB-9407144.

\section{References}

ÅGREN, J. AND SCHEMSKE, D. W. 1995. Sex allocation in the monoecious herb Begonia semiovata. Evolution, 49, $121-130$.

ASHMan, T. 1994a. A dynamic perspective on the physiological cost of reproduction in plants. Am. Nat., 144, $300-316$.

ASHMAN, T. 1994b. Reproductive allocation in hermaphrodite and female plants of Sidalcea oregana ssp. spicata (Malvaceae) using four currencies. Am. J. Bot., 81, 433-438.

CAMPBELL, D. R. 1989a. Measurements of selection in a hermaphroditic plant: variation in male and female pollination success. Evolution, 43, 318-334.

CAMPBELL, D. R. 1989b. Inflorescence size: test of the male function hypothesis. Am. J. Bot., 76, 730-738.

CAMPBELL, D. R. 1992. Variation in sex allocation and floral morphology in Ipomopsis aggregata (Polemoniaceae). Am. J. Bot., 79, 516-521.
CAMPBELL, D. R. 1996. Evolution of floral traits in a hermaphroditic plant: field measurements of heritabilities and genetic correlations. Evolution, 50, 1442-1453.

CAMPBELL, D. R. 1997. Genetic and environmental variation in life-history traits of a monocarpic perennial: a decade-long field experiment. Evolution, 51, 373-382.

CAMPBEll, D. R. AND halama, K. J. 1993. Resource and pollen limitations to lifetime seed production in a natural plant population. Ecology, 74, 1043-1051.

CAMPBell, D. R., WASER, N. M., PRICE, M. V., LYNCH, E. A. AND MITCHELl, R. J. 1991. Components of phenotypic selection: pollen export and flower corolla width in Ipomopsis aggregata. Evolution, 45, 1458-1467.

CAMPBEll, D. R., WASER, N. M. AND PRICE, M. V. 1994. Indirect selection of stigma position in Ipomopsis aggregata via a genetically correlated trait. Evolution, 48, 55-68.

CAMPBell, D. R., WASER, N. M. AND PRICE, M. V. 1996. Mechanisms of hummingbird-mediated selection for flower width in Ipomopsis aggregata. Ecology, 77, 1463-1472.

CHAPIN, F. S. 1989. The cost of tundra plant structures: evaluation of concepts and currencies. Am. Nat., 133, $1-19$.

CHARLESWORTH, B. 1990. Optimization models, quantitative genetics, and mutation. Evolution, 44, 520-538.

CHARlesworth, B. AND CHARlesworth, D. 1978. A model for the evolution of dioecy and gynodioecy. Am. Nat., 112, 975-997.

CHarlesworth, D. ANd Charlesworth, B. 1981. Allocation of resources to male and female functions in hermaphrodites. Biol. J. Linn. Soc., 15, 57-74.

CHARlesworTh, D. AND CHARLESWORTH, B. 1987. The effect of investment in attractive structures on allocation to male and female functions in plants. Evolution, 41, 948-968.

Charnov, E. L. 1982. The Theory of Sex Allocation. Princeton University, Princeton, NJ.

DELPH, L. F. AND MEAGHER, T. R. 1995. Sexual dimorphism masks life history trade-offs in the dioecious plant Silene latifolia. Ecology, 76, 775-785.

FALCONER, D. S. 1989. Introduction to Quantitative Genetics, 3rd edn. John Wiley and Sons, New York.

GOLdMAN, D. A. 1991. Minimal male/female tradeoffs in Zizania palustris, a monoecious annual grass. Am. J. Bot., 78, 189-197.

HOULE, D. 1991. Genetic covariance of fitness correlates: what genetic correlations are made of and why it matters. Evolution, 45, 630-648.

HOULE, D. 1992. Comparing evolvability and variability of quantitative traits. Genetics, 130, 195-204.

LAPORTE, M. M. AND DELPH, L. F. 1996. Sex-specific physiology and source-sink relations in the dioecious plant Silene latifolia. Oecologia, 106, 63-72.

LLOYD, D. G. 1979. Parental strategies in angiosperms. $N$. Z. J. Bot., 217, 595-606.

LLOYD, D. G. 1984. Gender allocations in outcrossing cosexual plants. In: Dirzo, R. and Sarukhan, J. (eds) 
Perspectives on Plant Population Ecology, pp. 277-300. Sinauer Associates, Sunderland, MA.

LOVETT DOUST, J. AND HARPER, J. L. 1980. The resource costs of gender and maternal support in an andromonoecious umbellifer, Smyrnium olusatrum L. New Phytol., 85, 251-264.

MITCHeLl, R. J. 1994. Effects of floral traits, pollinator visitation, and plant size on Ipomopsis aggregata fruit production. Am. Nat., 143, 870-889.

REZNICK, D. N. 1985. Cost of reproduction: an evaluation of the empirical evidence. Oikos, 44, 257-267.

SAKAI, A. K. AND WELLER, s. G. 1991. Ecological aspects of sex expression in subdioecious Schiedea globosa (Caryophyllaceae). Am. J. Bot., 78, 1280-1288.

SIMMS, E. L. 1992. Costs of plant resistance to herbivory. In: Fritz, R. S. and Simms, E. L. (eds) Plant Resistance to Herbivores and Pathogens, pp. 392-425. University of Chicago, Chicago, IL.
STANTON, M. L. AND GALLOWAY, L. F. 1990. Natural selection and allocation to reproduction in flowering plants. In: Mangel, M. (ed.) Sex Allocation and Sex Change: Experiments and Models, pp. 1-50. American Mathematical Society, Providence, RI.

STANTON, M. L. AND PRESTON, R. E. 1988. Ecological consequences and phenotypic correlates of petal size variation in wild radish, Raphanus sativus (Brassicaceae). Am. J. Bot., 75, 528-539.

VAN NOORDWIJK, A. J. AND DE JONG, G. 1986. Acquisition and allocation of resources: their influence on variation in life history tactics. Am. Nat., 128, 137-142.

WASER, N. M. AND PRICE, M. v. 1989. Optimal outcrossing in Ipomopsis aggregata: seed set and offspring fitness. Evolution, 43, 1097-1109.

YAMPOLSKY, E. AND YAMPOLSKY, H. 1922. Distribution of sex forms in phanerogamic flora. Bibliotheca Genetica, $3,1-62$. 